\title{
Miraa Use Among Somali Youth Living in Eastleigh, Nairobi Kenya
}

\author{
Eunice Jemalel Nyavanga ${ }^{1,2}$ \\ ${ }^{1}$ Department of Social and Human Development, Faculty of Social Sciences and Technology, The Technical University of Kenya, Nairobi, \\ Kenya \\ ${ }^{2}$ Malel-Bibwob Clinical Psychologists Consultancy Limited, Nairobi, Kenya
}

\section{Email address:}

enyavanga $a y$ yahoo.com, emalel.nyavanga $a$ gmail.com

\section{To cite this article:}

Eunice Jemalel Nyavanga. Miraa Use Among Somali Youth Living in Eastleigh, Nairobi Kenya. European Journal of Preventive Medicine. Vol. x, No. x, 2018, pp. 45-52. doi: 10.11648/j.ejpm.20180604.12

Received: June 22, 2018; Accepted: August 29, 2018; Published: September 25, 2018

\begin{abstract}
Eastleigh is a suburb in Nairobi inhabited predominantly by Somalis and known for a number of activates that includes businesses, stop over of youth people from the western world on their way to Somalia or to learn the culture and get spouses. Miraa use has been associated with the Somali community. The area of study was chosen as Section 1 from the four Sections that approximately hold 9408 households. 270 households were selected with at least one youth aged between 18-25 years of age. We gave our own developed questionnaire that asked about demographic characteristics and patterns of miraa use to consenting participants. Descriptive analysis was done based on the demographic characteristics. We found that miraa use was high (47.9\%) and was more prevalent among the males, those with lower educational level, the single (including the divorced and separated) and those born out of Eastleigh. We also found that miraa use was more prevalent among those whose parents were not married, living alone, with friends, relatives, parents and relatives, the unemployed, those running businesses, the self-employed and those whose families had lower income. Miraa onset was more likely at 18 years or below and was used with other psychoactive substances that include amphetamines, cannabis, heroin, cocaine, shisha, tobacco products and alcoholic beverages. A larger study should be done in this area that includes all the other sections as well. This study advises on targeting prevention of miraa use to youth younger than 18 years.
\end{abstract}

Keywords: Miraa, Khat, Somali Youth

\section{Introduction}

Miraa also known as khat (Catha edulis) is an evergreen plant that grows in Kenya mainly in the Meru region and Ethiopia in Africa. It is an indigenous plant to both Ethiopia and Yemen although now spread to other East African Countries that include Kenya. This plant has been used for many centuries as a mild psycho-stimulant, [1]. The stimulating effect comes from the alkaloid cathinone, that has similar chemical effects to amphetamine, [2]. This stimulating effect is associated with poor sleep among users, among College students in Ethiopia [3]. The fresh twigs with leaves are harvested and chewed or used as a tea. In Kenya, miraa is distinguished to be miraa and muguka, but this study will call all of them miraa.

\subsection{Effects of Miraa}

Miraa use has been associated with being male, Muslim, and having multiple sexual partners, [4-8]. Miraa has been reported to have lots of mental health effects on humans that include inducing psychotic symptoms, depression, dependence increase sleep and negative mood disturbances, higher levels of distress to likely induce memory deficits, and cognitive flexibility, "[9-14]". In addition, miraa use has been seen to increase physical health problems that include gastrointestinal disorders, high blood pressure, heart failure, autoimmune hepatitis, poor health among those living with HIV/AIDS, poor physical health problems, low birth weight among pregnant women, H. pylori infection, and under nutrition,. "[15-22]". All the above lead to increased financial problems, poor academic functioning and poorer quality of life, [23]. 
Furthermore, miraa use has been seen to be used with other psychoactive substances, that include tobacco, alcohol, and other psychoactive substances, "[4, 19, 24-25]". Those living with HIV/AIDS and taking ARVs are more likely not to adhere to medication, [4].

\subsection{Importance of Prevalence of Miraa Use among Somali Youth}

The National Authority for the Campaign Against Alcohol and Drug Abuse, (NACADA), in a rapid situation assessment of the status of drug and substance abuse in Kenya, 2012, [reported that the youth (10-14 years of age) are highly aware of miraa $(87.5 \%)$ in Nairobi compared to those of the country, $(78.5 \%)$. The same report indicates a $7.2 \%$ upresent use in Nairobi, compared to $4.2 \%$ use in the country. In addition miraa use has been reported

Eastleigh is a suburb in Nairobi that was founded in 1921 originally to accommodate the Asian Community created by the colonial government, till independence in 1963. Today, mostly the Somali immigrants, except a few indigenous residents and other immigrants from Ethiopia and Eritrea dominate Eastleigh. The Somali Community engages in businesses that range from small stalls to large shopping malls and night lodges. A number of Somali immigrants from the Western World have a stopover in Eastleigh as they go to Somalia, or young people send to live with other relatives and learn the culture or get spouses in Eastleigh from arranged marriages.

British-Somali young men have been reported to use miraa that offers them a sense of cultural identity and belonging that is done in great secrecy and for leisure practices, [26]. A study among Somali refugees living in Nairobi indicated a high level of Post Traumatic Stress Disorder (PTSD) symptoms among those who frequently used miraa, [27].

\section{Methodology}

\subsection{Study Area and Population}

This study was done in Eastleigh suburb in Nairobi city of Nairobi among Somali Community youth, between the ages of 18-25 years.

\subsection{Study Design and Sampling}

This study is exploratory cross-sectional survey study, which is part of a larger study namely "Prevalence and Patterns of Psychoactive Substance Use and its Associated Demographic Characteristics among Somali Community Youth Living in Eastleigh, Nairobi Kenya". Out of the estimated 9408 households, 270 households were sampled to identify at least one youth in each household.

\subsection{Ethical Considerations}

The Kenya Methodist University Research Ethics Committee, which sets forth research ethics concerning individual's personal data, approved this study. With this approval, we sought clearance from the Ministry of Education, the research Department before data collection. We also met the Nairobi Provincial Administration, to inform them of the purpose, plan and implication of the study, before asking them in planning data collection.

The participants were met in their households, explained the purpose, plan and implications of the study before asking for their verbal consent. We presented a cover letter to explain the purpose, plan and implications of the study. It was also explained to them that their identity would be kept confidential as no names or numbers would be put in the questionnaires and the results. They will also be informed that participating is voluntary, with no payment, and they can discontinue at any stage of the study, without any penalty.

The questionnaire was pre=tested in Laini Saba, Kibera suburb in Nairobi to determine validity and reliability and the pre-test data was analyzed to determine practicability.

\subsection{Data Management}

Researcher-developed questionnaire was used to interview the participants while at their homes with the use of research assistants who were very conversant with the area. This questionnaire asked the participants on their demographic characteristics, use of miraa and other psychoactive substances, and pattern of use in the last 12 months. Collected data was cleaned, coded accordingly before entry into SPSS template builder and both descriptive and inferential statistics were performed

\section{Results}

\subsection{Introduction}

This study sought to determine miraa use among Somali youth between the ages of 18-25 years of age in Eastleigh a suburb of Nairobi, Kenya. The prevalence of use based on socio-demographic and socio-economic characteristics, comorbidity with other psychoactive substances, and age of onset.

\subsection{Participants Characteristics}

Most of the participants were between ages, 24-25, (33.8\%) followed ages $18-19,(24.4 \%)$, then by ages $22-23$, $(23.9 \%)$, then the least were those of ages $20-21$ who were $17.8 \%$. The majority was male, at $58.2 \%$. The singles were $65.7 \%$, the married were $25.8 \%$ while the separated were $1.9 \%$. $37.6 \%$ reported to have secondary education as the highest level of education, while 24.45 had primary and below education; while those with diploma were $15.5 \%$; those with certificate training were $12.2 \%$ while those in middle colleges were $7.0 \%$ and the post graduate and undergraduate level of education were $2.3 \%$ and $0.9 \%$ respectively.

The majority (42.7\%), were unemployed while $23.9 \%$ reported they were students and $18.8 \%$ were employed, the self-employed and those engaged in business were $9.4 \%$ and 
$5.2 \%$ respectively. Most reported to live with parents, $(34.7 \%)$, while $12.2 \%$ live with other relatives, $10.3 \%$ live alone while $9.9 \%$ live with parents and other relatives and $8.0 \%$ live with friends. The majority $70.9 \%$ reported to have moderate family income. $67.1 \%$ had married parents; while $56.8 \%$ reported do have been born in Eastleigh.

\subsection{Prevalence of Miraa Use}

Table 1. Shows the Prevalence of Miraa Use.

\begin{tabular}{lll}
\hline & No. & Percentage \\
\hline Prevalence of Khat (Miraa) & 102 & $47.9 \%$ \\
\hline $47.9 \%$ participants used miraa & &
\end{tabular}

\subsubsection{Prevalence of Miraa Use Per Socio-Demographic Characteristics}

Table 2. Prevalence of Miraa Use based on Socio-demographic characteristics.

\begin{tabular}{|c|c|c|c|}
\hline \multirow{2}{*}{ Socio-Demographic Characteristics } & & \multicolumn{2}{|c|}{ Khat (Miraa) } \\
\hline & & $\mathbf{n}$ & $\%$ \\
\hline \multirow{3}{*}{ Age } & $18-19$ & 21 & $40.4 \%$ \\
\hline & $22-23$ & 26 & $51.0 \%$ \\
\hline & $24-25$ & 35 & $48.6 \%$ \\
\hline \multirow{2}{*}{ Gender } & Male & 69 & $55.6 \%$ \\
\hline & Female & 32 & $36.4 \%$ \\
\hline \multirow{5}{*}{ Highest level of education completed } & Primary and Below & 36 & $69.2 \%$ \\
\hline & Secondary Education & 36 & $45.0 \%$ \\
\hline & Middle College Education & 8 & $53.3 \%$ \\
\hline & Certificate & 10 & $38.5 \%$ \\
\hline & Diploma & 11 & $33.3 \%$ \\
\hline \multirow{6}{*}{ Marital status } & Married & 14 & $25.5 \%$ \\
\hline & Single & 75 & $53.6 \%$ \\
\hline & Divorced & 10 & $76.9 \%$ \\
\hline & Separated & 2 & $50.0 \%$ \\
\hline & Widowed & 0 & $0.0 \%$ \\
\hline & Other & 1 & $100.0 \%$ \\
\hline \multirow{2}{*}{ Born in Eastleigh } & No & 49 & $53.3 \%$ \\
\hline & Yes & 53 & $43.8 \%$ \\
\hline
\end{tabular}

Based on age, miraa use was high among those of 20-21 years, $(52.6 \%)$, followed by those of $22-23$ years, $(51.9 \%)$, then $24-25$ years, (48.6\%), and lowest among those of 18-19 years, $(48.6 \%)$. The males had a higher miraa use of $55.6 \%$ compared to the female $\mathrm{s}$ that reported a lower use of $36.4 \%$. Highest use of miraa was indicated among those of primary and below educational level, (69.2\%), and middle college

\subsubsection{Miraa use Based on Socio-Economic Characteristics}

Table 3. Miraa use based on Socio-Economic Characteristics.

\begin{tabular}{|c|c|c|c|}
\hline & & \multicolumn{2}{|c|}{ Khat (Miraa) } \\
\hline & & $\mathbf{n}$ & $\%$ \\
\hline \multirow{2}{*}{ Parents married } & No & 43 & $61.43 \%$ \\
\hline & Yes & 59 & $41.26 \%$ \\
\hline \multirow{5}{*}{ Occupation } & Self employed & 9 & $45.00 \%$ \\
\hline & Business & 6 & $54.55 \%$ \\
\hline & Employed & 13 & $32.50 \%$ \\
\hline & Unemployed & 63 & $69.23 \%$ \\
\hline & Student & 11 & $21.57 \%$ \\
\hline Living Conditions & I live with my parents & 29 & $39.19 \%$ \\
\hline
\end{tabular}

education, (53.3\%), compared to a lower use of $14.3 \%$ among the undergraduate level of education. Higher use was reported among the divorced, (76.9\%), the singles, (53.6\%) and the separated, $(50.0 \%)$, compared to the married, $(25.5 \%)$, and the widowed, $(0.00 \%)$. Those born out of Eastleigh reported a higher miraa use of $53.3 \%$ compared to those born in Eastleigh, (43.8\%). 


\begin{tabular}{llll}
\hline & Khat (Miraa) & \% \\
\cline { 2 - 3 } & & $\mathbf{n}$ & $46.15 \%$ \\
\cline { 2 - 3 } & I live with relatives & 12 & $70.59 \%$ \\
& I live with friends & 12 & $72.73 \%$ \\
& I live alone & 16 & $42.86 \%$ \\
I live with parents and other relatives & 9 & $27.50 \%$ \\
I live with spouse/partner & 11 & $100.00 \%$ \\
Other & 13 & $0.00 \%$ \\
Very High & 0 & $37.50 \%$ \\
High & 6 & $41.72 \%$ \\
& Moderate & 63 & $64.29 \%$ \\
Low & 18 & $90.91 \%$ \\
& Very Low & 10 & $100.00 \%$ \\
\hline
\end{tabular}

Participants whose parents were not married indicated a higher miraa use compared to those whose parents were not married, $41.26 \%$. Based on occupation, higher miraa use was reported among the unemployed, (69.23\%), those in business, $54.55 \%$, the self-employed, $45.00 \%$, compared to a lower use among the employed, (32.50\%) and students, $21.5 \%$. Higher use was found among participants living alone, $(72.73 \%)$, living with friends, $(70.59 \%)$, compared to a lower use of those living with relatives, $46.15 \%$, those living with parents and relatives, (42.86\%), those living with their parents, (39.19\%) and those living with spouse/partner, $(27.50 \%)$. Based on family income, miraa use was higher among those who did not know, $(100 \%)$, very low income, (90.91\%), low income, 64.29\%, compared to a lower use among those with moderate income, $(41.72 \%)$, high income, $(37.50 \%)$ and very high income, $(0.00 \%)$.

\subsection{Age Onset of Miraa Use}

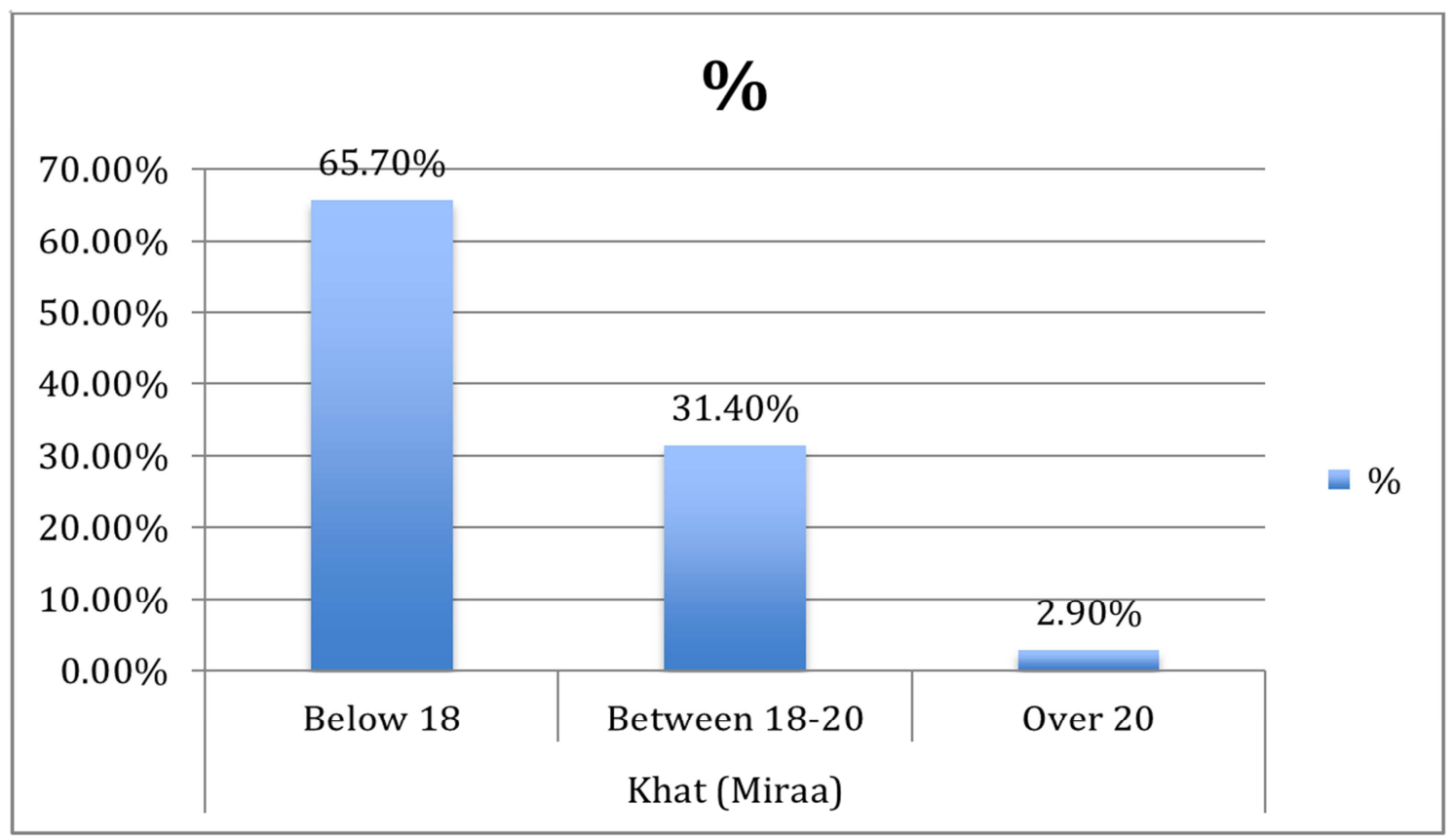

Age onset of miraa use was higher at 18 years and below (65.7\%), compared to $19-23$ years, $(31.40 \%)$ and over 23 years of age, $(2.9 \%)$

Figure 1. Miraa use age of onset. 


\subsection{Comorbidity of Miraa Use and Other Psychoactive Substances}

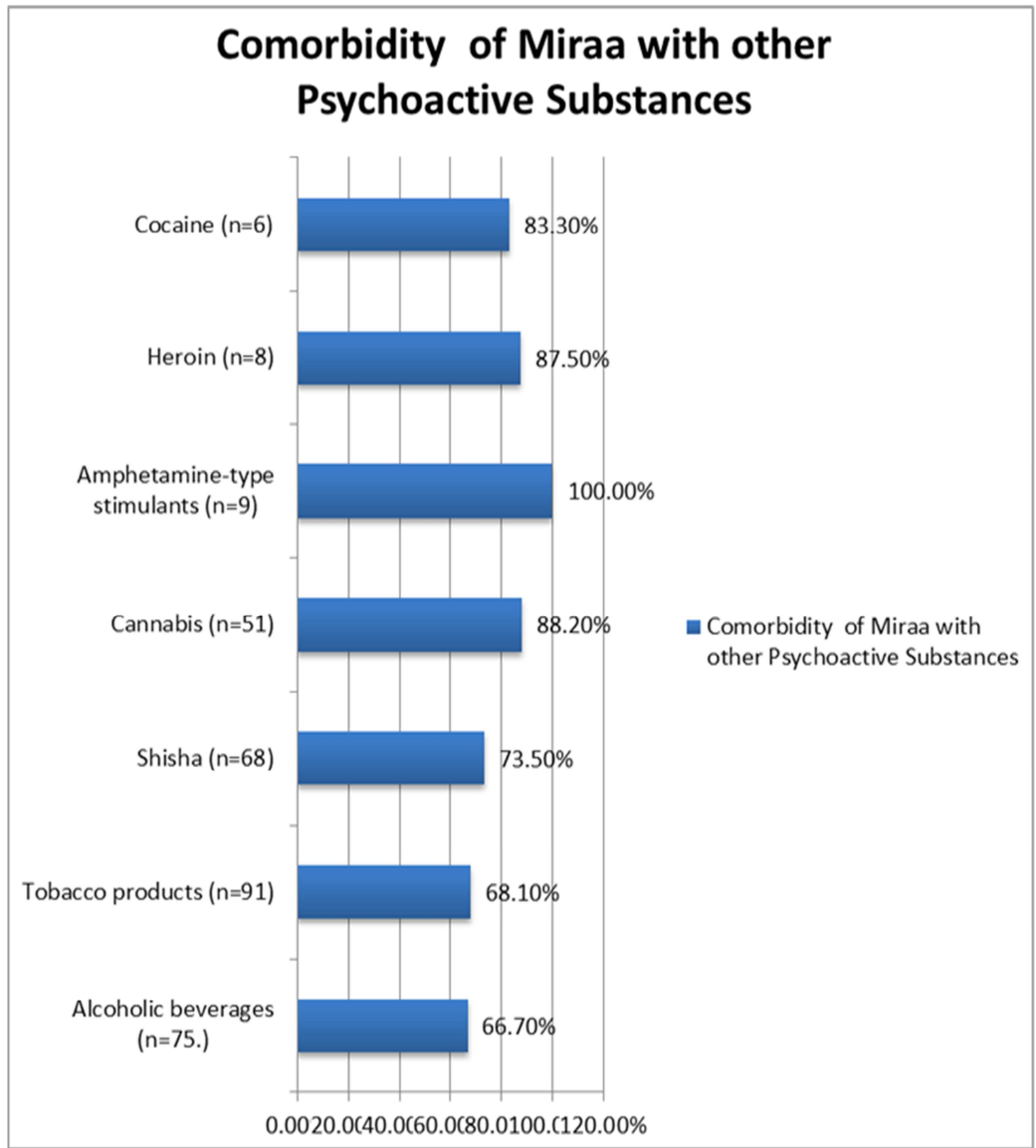

Figure 2. Comorbidity of Miraa use With Other Psychoactive Substances.

Miraa use was used with other psychoactive substances that included, amphetamines, (100.00\%), cannabis, (88.20\%), Heroin, 87.5\%, cocaine, (83.30\%) shisha, $(73.50 \%)$, tobacco products, $(68.10 \%)$, and alcoholic beverages, $(66.7 \%)$.

\section{Discussion}

\subsection{Introduction}

This study aimed at determining miraa use among Somali youth between the ages of 18-25 years living in Eastleigh, a Nairobi suburb based on demographic characteristics, family social-economic characteristics, the age of onset and comorbidity with other psychoactive substances in the last one year.

\subsection{Prevalence of Miraa Use}

This study found a high prevalence of miraa use of $47.9 \%$. This is similar to other studies, among Australian youth immigrants from Africa, 44.2\%, [20], among individuals in the USA, 35\%, [24] but lower than those reported by patients entering HIV treatment in Ethiopia, $65 \%$ "[19-20, 24]". This findings is higher than that found among university students of Gonder in North West Ethiopia, that recorded $16.4 \%$, that indicated by Kassim et 
al, 2015, among tobacco users that showed 16-30\% use, and that of people in contact with HIV services in South West Ethiopia, 23.0\%, "[4, 28-29]".

\subsection{Prevalence of Miraa Use Per Socio-Demographic Characteristics}

This study found that those between the ages of 20-21, 2223 and 24-24 had a higher miraa use of $52.5 \%, 51.0 \%$ and $48.6 \%$ respectively compared to those of $18-19$ years of age, which recorded a $40.4 \%$. We did not find any study to compare with, but we attributed this gradual increase to the idea that most miraa users begin to use at an early age and increase use of time. This study reported a higher miraa use of $55.6 \%$ among male compared to females, $36.4 \%$. This is similar to other studies, "[4, 28]".

We found that miraa use was more prevalent among participants who had primary and below education, (69.2\%), middle college education, (53.3\%), secondary education, $(45.0 \%)$ and certificate education, (38.5\%), compared to a lower use among diploma education (33.3\%) and undergraduate education (14.3\%). This is similar to other studies; Kinoti et al, 2011 reported the higher level of education was associated with less miraa use among a rural population in Kenya, [30]. In addition, Chege et al, 2017 have also reported a lower educational level to be associated with higher psychoactive substance use among youth receiving rehabilitation treatment in Mombasa in Kenya, [31].

We found that the divorced and those who are single had a higher miraa use of $76.9 \%$ and $53.6 \%$ respectively; compared to the married, who indicated a lower use $25.5 \%$. This is partly similar to findings of Mihretu et al, 2017 in an expletory study among individuals using miraa in Ethiopia, [25]. They reported that those who were single had higher miraa use of $69.6 \%$ compared to the married, $23.5 \%$, but the divorced had a much lower use of 5.9\%. However, a study in Saudi Arabia, reported a higher miraa use among the married at $60.8 \%$ compared to the single at $32.6 \%$, [32]. This finding is similar to what was reported among patients entering an HIV treatment program in Ethiopia, [19].

This study found a higher miraa use among participants who were born out of Eastleigh, of $53.3 \%$ meaning they could have migrated to this area compared to those born in Eastleigh, (43.8\%). This is similar to other studies, that indicated that miraa use among immigrants from Eastern Africa and the Middle East to the Western world had higher miraa use, [17]. The same was also pointed by Young et al, 2016 among youth immigrants from Africa in Australia, [20].

We found that participants whose parents are married had a lower miraa use of $41.26 \%$ compared to those whose parents were unmarried, $61.43 \%$. We did not find any study on the prevalence of miraa use and parents marital status; however, Kassa et al, 2014 pointed out that family substance use history increased miraa use among Hawassa University students in Ethiopia, [33].

\subsection{Prevalence of Miraa Use and Socio-Economic Characteristics}

This study indicated that participants who were unemployed, held a business, and self-employed had a higher miraa use of $69.23 \%, 54.55 \%$ and $45.00 \%$ respectively compared to a lower use among the employed, and the students of $32.50 \%$ and $21.57 \%$ respectively, [19]. This is similar to other studies, Lifson et al, 2017 reported a high miraa use among the unemployed at $60 \%$. However, Haile \& Lakew, 2015 also indicated a higher miraa use among those with occupations that includes sales, agriculture, service sector and manual work to have a higher miraa use compared to those with no occupation, [6].

We found that participants with a higher miraa use were those who lived alone, with friends, relatives, parents and relatives of $72.73 \%, \quad 70.59 \%, \quad 46.15 \%$ and $42.86 \%$ respectively compared to those who lived with parents and students at $39.19 \%$ and $27.50 \%$ respectively. This finding is similar to other findings; Kassa et al, 2014 reported higher use when living alone, while Duresso et al, 2016 reported a high use when living with relatives and Adane et al, 2017 and Duresso et al 2017 found a higher use when living with friends, "[23, 28, 33]". We found that those with low, very low, and moderate family income, used miraa more than those with high and very high family income. This is similar to findings among university students in Central Ethiopia, Gebremariam et al, 2018, [34].

\subsection{Age of Onset of Miraa Use}

Age onset of miraa use was higher at 18 years and below (65.7\%), compared to $19-23$ years, $(31.40 \%)$ and over 23 years of age, $(2.9 \%)$. This is similar to other findings; Lifson et al 2017 indicated an early onset of miraa use to be below 19 years at 54\% among patients entering HIV treatment in Ethiopia, [19]. In addition, another study in Ethiopia indicated that about a half $(49.0 \%)$ of miraa users started to use before the age of 10 years, [25].

\subsection{Comorbidity of Miraa Use and Other Psychoactive Substances}

This study found that miraa use is comorbid with other psychoactive substances that include amphetamines, (100\%), cannabis, (88.20\%), Heroin, 87.5\%, cocaine, $(83.30 \%)$ shisha, $(73.50 \%)$, tobacco products, $(68.10 \%)$, and alcoholic beverages, $(66.7 \%)$. This is similar with other studies, miraa is used with cigarette smoking, "[4, 19, 28-29]". Miraa has also been found to be used with alcohol in other studies, [19, 28].

\section{Conclusion}

There is high prevalence of miraa use among these participants, which is associated with being male, having a lower educational level, being single, and being born out of Eastleigh. Miraa use is further associated with living conditions of living alone, living with friends, living with 
relatives, living with parents and relatives. Miraa use is associated with being unemployed, those with businesses and the self-employed and those whose families have a lower income. Miraa use onset is mainly at 18 years and below and associated with the use of other psychoactive substances that include amphetamines, cannabis, heroin, cocaine, shisha, tobacco products and alcoholic beverages.

\section{Recommendations}

Parents with young people in Eastleigh should monitor them closely in order to reduce onset of miraa and other psychoactive substances. Policy makers and implementers should target youth younger than 18 years of age to prevent miraa use spread among the youth in Eastleigh. Other researchers should identify other factors associated with miraa use especially other psychoactive substances to determine which substance is used before the others.

\section{References}

[1] Nichols, T., Khandkar, P., \& Gibbons, S., (2015). The psychostimulant drug khat (Catho endulis): A mini-review. Phytochemistry Letters, 13: 127-133.

https://doi.org/10.1016/j.phytol.2015.05.016.

[2] Getasetegn, M. (2016) Chemical composition of Catha edulis (khat): a review. Phytochemistry Reviews 15: 907. https://doi.org/10.1007/s11101-015-9435-z.

[3] Lemma, S., Patel, S. V., Tarekegn, Y. A. Tadesse, M. G., Berhane, Y., Gelaye, B. Williams, M. A. (2012). "The Epidemiology of Sleep Quality, Sleep Patterns, Consumption of Caffeinated Beverages, and Khat Use among Ethiopian College Students," Sleep Disorders, 2012; https://doi.org/10.1155/2012/583510.

[4] Soboka, M., Tesfaye, M., Feyissa, T., \& Hanlon, C. (2015). Khat use in People living with HIV: A facility-based crosssectional survey from Soouth West Ethiopoia. BMC Psychiatry, 15: 69. https://doi.org/10.1186/s12888-015-0446-5.

[5] Nakajima, M. Dokam, A., Alsameai, A., AlSoofi, M., Khalil, N., al'Absi, M. (2014). Severity of khat dependence among adult chewers: the moderating influence of gender and age. Journal of Ehnopharmocology; 155 (3): 1467-1472. https://doi.org/10.1016/j.jep.2014.07.030.

[6] Haile, D., \& Lakew, Y. (2015). Khat Chewing Practice and Associated Factors among Adults in Ethiopia: Further Analysis Using the 2011 Demographic and Health Survey. PLOS /ONE, 10 (16).

https://doi.org/10.1371/journal.pone.0130460.

[7] Berhanu, D., Diener-West, M., Ruff, A., Davis, W., Celentano, D. D., \& Go, V. F. (2017). Associations Between Khat Use and HIV Risk and Status Among Voluntary Counseling and Testing Center in Addis Ababa, Ethiopia. Journal of Addiction Medicine; 11 (4): 320-327. doi: 10.1097/ADM.0000000000000304.

[8] Kabede, D., Alem, A., Mitike, G., Enquselassie, F., Berhane, F., Abebe, Y., Ayele, R. Lemma, W., Assefa, T., \& Geremicheal, T. (2005). Khat and alcohol use and risky sex behavior among in-school and out-of-school youth in Ethiopia. BMC Public Health; 5: 109.

https://doi.org/10.1186/1471-2458-5-109.

[9] Adorjan, K., Oldenwald, M., Widmann, M., Tesfaye, M., Tessema, F., Toennes, S., et al, (2017). Khat use and occurrence of psychotic symptoms in the general male population in Southwestern Ethiopia: evidence for sensitization by traumatic expereincesWorld Psychiatry, 16 (3): 323..https://doi.org/10.1002/wps.20470.

[10] Widmann, M., Apondi, B., Musau, A., Warsame, A. H., Isse, M., Mutiso, V., Veltrup, C., Ndetei, D., \& Oldenwald, M. (2017). Comorbid psychopathology and everyday functioning in a brief intervention study to reduce khat use among Somalis living in Kenya: description of baseline multimorbidity, its effects of intervention and its moderation effects on substance use. Social Psychiatry and Psychiatric Epidemiology; 52 (11): 1425-1434. DOI https://doi.org/10.1007/s00127-017-1368-y.

[11] Nakajima, M., Hoffman, R., \& Al'Absi, M. (2017): Level of khat dependence, use patterns, and psychosocial correlates in Yemen: A Cross-sectional investigation. Eastern Mediterranean Health Journal; 23 (3): 161-167.

[12] Nakajuma, M., Jebena, M. G., Taha, M., Tesfaye, M., Gunida, E., Lemieux, A., Hoffman, R., \& al'Absi, M. (2017).

Correlates of khat use during pregnancy: A cross-sectional study. Addictive Behaviours; 73: 178-184. https://doi.org/10.1016/j.addbeh.2017.05.008.

[13] Manzar, D., Salahuddin, M., Sony, P., Maru, T. T., PandiPerumal, S. R., Moscovitch, A., \& Bahammam, A. S. (2017). Sleep disturbances and memory impairment among pregnant woment consuming khat: An under-recognized problem. Annals of Thoracic Medicine; 12 (4): 247-251. doi: 10.4103/atm.ATM_24_17.

[14] Kimani, S. T., Pate, 1, N. B., \& Kioy, P. G. Memory deficits associated with khat (Catha edulis) use in rodents. Metabolic Brain Disease; 31 (1): 45-52. DOI

https://doi.org/10.1007/s11011-015-9738-1.

[15] Hassan, M. A., Mohamed, K., Zipporah, N., \& Hudson, L. (2014). Khat (Catha edulis) Use is Associated with the Development of Gastritis among Adults in Nairobi County, Kenya, East African Medical Journal, 91 (6): 191-201.

[16] Jima, S. B., Tefera, T. B., \& Ahmed, M. B. (2015). Prevalence of Tobacco Consumption, Alcohol, Khat (Catha Edulis) Use and High Blood Pressure among Adults in Jimma Town, South West Ethiopia. Science Journal of Public Health, 3 (5): 650-654. doi: 10.11648/j.sjph.20150305.19.

[17] El-Menyar, A., Mekkodathikm A., Al-Thani, H., \& AlMotarreb, A. (2015). Khat Use: History and Heart Failure. Oman Medical Journal; 30 (20: 77-82. doi: 10.5001/omj.2015.18.

[18] Samies, J., Slehria, S., Chen, X., Vaidya, S., \& Saleem, N. (2016). Chronic Khat (Catha Edulis) Ingestion as a possible Triggering Agent in the Development of Autoimmune Hepatitis. Journal of Medical Cases; 7 (11): 471-474. doi: http://dx.doi.org/10.14740/jmc2598w.

[19] Lifson, A. R., Workneh, S., Shenie, T., Ayana, D. A., Melaku, Z., Bezabih, L. et al, (2017). Prevalence and factors associated with use of khat: a survey of patients entering HIV treatment programs in Ethiopia. Addiction Science and Clinical Practice; 12: 3. https://doi.org/10.1186/s13722-016-0069-2. 
[20] Young, J. T., Butt, J., Hersi, A., Tohow, A., \& Mohamed, D. H. (2016). Khat Dependence, Use Patterns, and Health Consequences in Australia: An Exploratory Study. Journal of Studies on Alcohol and Drugs; 77 (2): 343-349. https://doi.org/10.15288/jsad.2016.77.343.

[21] Tesfay, K., Abera, M., Wondafrash, M., \& Tesfaye, M ((2018). Effect of Khat Use During Pregnancy on the Birth Weigh of Newborn in Jimma, Ethiopia. Internatioonal Journal of Mental Health and Addiction: 1-10. DOI https://doi.org/10.1007/s11469-018-9888-6.

[22] Legesse, T. G., Takle, Z. J., \& Best, M. G. (2017). Effect of Khat and Associated Factors on Nutritional status among Khat Chewers at Gulelle sub-city, Addis Ababa, Ethiopia. International Journal of food Science and Nutirition Enginering. 7 (1): 11-18.

http://creativecommons.org/licenses/by/4.0/

[23] Duresso, S. W., Matthews, A. J., Ferguson, S. G., \& Bruno, R. (2010). Is khat use disorder a valid diagnostic entity? Addiction; 111 (9): 1666-1676. https://doi.org/10.1111/add.13421.

[24] Nakajima, M., Molla, K., Belachew, B., Mohammed, A., Hassan, A., Kroll, J., \& al'Absi, M. (2017). Khat Use is Assciated with Tobacc, Alcohol, and Illicit Drug Use: A Cross-Sectional Examination in the United States. Journal of Psychoactive Drugs; 49 (5): 413-419. https://doi.org/10.1080/02791072.2017.1342155.

[25] Mihretu, A., Teferra, S., \& Fekadu, A. (2017). Problematic khat use as a possible risk factor for harmful use of other psychoactive substances: a mixed method study in Ethiopia. Substance Abuse Treatment, Prevention and Policy; 12: 47. https://doi.org/10.1186/s13011-017-0132-3.

[26] Swain, S., Spracklen, K. \& Lashua, B. D. (2018). Khatchewing in liminal leisure spaces: British-Somali youth on the margins. Leisure Studies, DOI: 10.1080/02614367.2018.1455891.

[27] Widmann, M., Warsame, A. H., Mikukica, J., von Beust,, J., Isse, M. M., Ndetei, D., al'Absi, M., \& Odenwald M. G.
(2014). Khat use, PTSD and psychotic symptoms among Somali refugees in Nairobi - a pilot study. Frontiers in Public Health, 2 (71): 1-10. https://doi.org/10.3389/fpubh.2014.00071.

[28] Adane, W. G., Alemie, G. A., W/yhonnes, S. M., Gelaw, Y. S. (2016). Prevalence and associated factors of khat use among university students in the University of Gondar, Northwest Ethiopia. Journal of Substance Use; 22 (2): 176-181. https://doi.org/10.3109/14659891.2016.1166273.

[29] Kassim, S. Jawad, M., Croucher, R. \& Akl, E. A. (2015). The Epidemiology of Tobacco Use among Khat Users: A systematic Review. Biomed Research International; 2015 (ID 313692): 9 pages. http://dx.doi.org/10.1155/2015/313692.

[30] Kinoti, K. E., Jason, L. A., \& Harper, G. W. (2011). Determinants of Alcohol, Khat, and Bhang Use in Rural Kenya. African Journal of Drug and Alcohol Studies; 2 (10); 107-118.

[31] Chege, R. W., Mungai, P. G., \& Oresi, S. N. An investigation of the factors contributing to drug and substance abuse among the youth in Kenya: A survey of select rehabilitation centers in Mombasa County. International Journal of Public Health; 1 (5): 53-70.

[32] Mahfour, M. S., Rahim, B. E. A., Solan, Y. M. H., Makeen, A. M,. \& Alsanosy, R. M. (2015). Khat Chewing Habits in the Population of the Jazan Region, Saudi Arabia: Prevalence and Associated Factors. PLOS/ ONE; 10 (8): 1-8. doi: 10.1371/journal.Pone.0134545.

[33] Kassa, A., Taddesse, F. and Yilma, A. (2014). Prevalence and factors determining psychoactive substance (PAS) use among Hawassa University (HU) undergraduate students, Hawassa Ethiopia. BMC Public Health; 14: 1044. https://doi.org/10.1186/1471-2458-14-1044.

[34] Gbremariam, T. B., Mruts, K. B . \& Neway, T. K. (2018). Substance use and associated factors among Debre Berhan University Students, Central Ethiopia. Substance Abuse Treatment, prevention and Policy; 13: 13. https://doi.org/10.1186/s13011-018-0150-9. 